Research Article

\title{
A Descriptive Study to Assess the Association of Social Media Usage on Family Relationship among Student Nurses in Selected College of Nursing in Delhi
}

\author{
Anju Hooda', Suchhanda Bhattacharya ${ }^{2}$ \\ 1,2Tutor, Rufaida College of Nursing, Jamia Hamdard, Delhi, India. \\ DOI: https://doi.org/10.24321/2455.9318.202103
}

\section{I $\quad \mathbf{N} \quad \mathbf{F} \quad \mathbf{O}$}

\section{Corresponding Author:}

Suchhanda Bhattacharya, Rufaida College of Nursing, Jamia Hamdard, Delhi, India.

E-mail Id:

suchhanda.joarder@gmail.com

Orcid Id:

https://orcid.org/0000-0001-5450-5491

How to cite this article:

Hooda A, Bhattacharya S. A Descriptive Study to Assess the Association of Social Media Usage on Family Relationship among Student Nurses in Selected College of Nursing in Delhi. Int J Nurs Midwif Res. 2021;8(1):14-17.

Date of Submission: 2021-02-20

Date of Acceptance: 2021-03-07

\section{$\begin{array}{llllllll}\mathbf{A} & \mathbf{B} & \mathbf{S} & \mathbf{T} & \mathbf{R} & \mathbf{A} & \mathbf{C} & \mathbf{T}\end{array}$}

Introduction: Social media sites have become the most popular mode in recent years to communicate with people and share interests and likes with others. One of the many influences of social media is change in family relationships resulting from a decline in quality time spent with the family especially among youths including students. So the objective of the present study was to assess the effect of social media usage on family relationship.

Method: A descriptive survey was conducted on 124 student nurses studying at Rufaida College of Nursing, selected by purposive sampling technique. Structured rating scale and Brief Family Relationship Scale were used to assess social media usage and family relationships of student nurses on three parameters, expressiveness, cohesion, and conflicts. Data were analysed using descriptive and inferential statistics. Linear correlation was used to find the correlation between social media usage and family relationship.

Result: The assessment of family relationships indicated maximum expressiveness among families of 76 students, maximum cohesion among families of 115 students, and moderate conflicts among families of 58 students. In the linear correlation, there is a direct relationship of cohesion and expressiveness in the family and social media usage and inverse relationship of conflict within the family and social media usage.

Conclusion: There seems to be a direct correlation between social media usage and expressiveness and cohesion within the family and an inverse relationship between conflict and social media usage in the family.

Keywords: Social Media Usage, Family Relationship, Student Nurses

\section{Introduction}

Social network sites are playing an important part in human beings' existence and more than a billion people are connected to them in their daily lives. The use of these social network sites by many people has a meaningful 
social impact and has completely affected the daily lives of people all over the world. The users have excessive interaction chances during social networking, therefore people can share almost everything in their social life, such as information, ideas, pictures, events, and news, with their friends or even with strangers (or virtual friends) on social media sites. ${ }^{1}$

According to Global Digital Overview, January 2019, there were around 3.48 billion social media users in 2019 . With the worldwide population increasing by approximately 2.88 billion i.e. $9 \%$ since last year, the number of people using social media platforms has also shown a rise, increasing to around 3.56 billion. ${ }^{2}$

Nowadays, social networking sites such as Facebook, YouTube, Twitter, Tumbler, Snapchat, WhatsApp, Instagram and others are attracting millions of people around the world, especially students. Social media has been the source of happiness for many students. Social media have become a trending topic nowadays and is viral among young adulthood which may affect the relationships between the parents and their children in different age groups.

This research has been conducted to examine or rather discuss the positive as well as negative impact of social media usage on family relationships. Psychologists have been verbalising a concern on how social media usage is breaking the harmony of communications in families. They also emphasise on how this can directly or indirectly reduce the span of attention given by family members to each other.

On the brighter side, it cannot be denied how technology has helped families to maintain communication when long distances come into the picture. They have helped us in keeping a track of locations or keeping up with where our family members are going or will go.

There is no denying how, many times, technology accumulates a negative to zero interaction between siblings or even a parent and a child. We humans have always been quoted to be 'social animals' and that is how humans are directly or indirectly interdependent on each other to satisfy or maintain their social bonding. Social media has put a rather question mark on it by hampering this belief as the coming generations have started taking up social involvement to be a rather choice and they feel more comfortable in maintaining social relations via their technological devices.

\section{Methodology}

A cross-sectional descriptive study was conducted to assess the social media site usage and family relationship of student nurses.

The study was conducted from June to September 2020. It included 124 student nurses of first years of undergraduate courses (BSc Hons Nursing, DGNM, and Post basic BSc Nursing) selected using purposive sampling at a selected nursing college of Delhi (Rufaida College of Nursing) after obtaining ethical approval and administrative permission to conduct the study. The participants were given full explanation of the objectives of the study and assured of maintenance of confidentiality of their responses. The data were obtained after informed consent was taken. The study included only first year students of UG courses and those who can access Google Form. Those who were not willing to participate in the study were excluded. Based on the objectives of the study, structured questionnaire was used to assess the demographic profile and social media usage of students. Brief family relationship scale was used to assess the relationship within the family as expressed by student nurses. The social media usage was divided into three categories - low usage, medium usage, and excessive usage, according to the time spent surfing social media sites by the students. The family relationship scale assessed three parameters of relationship, cohesiveness, expressiveness, and conflict within the family of the students. Descriptive analysis such as percentage, frequency, mean, SD, and linear correlation between social media usage and family relationship was calculated.

\section{Result}

\section{Section I: Findings related to Demographic Data of the Student Nurses}

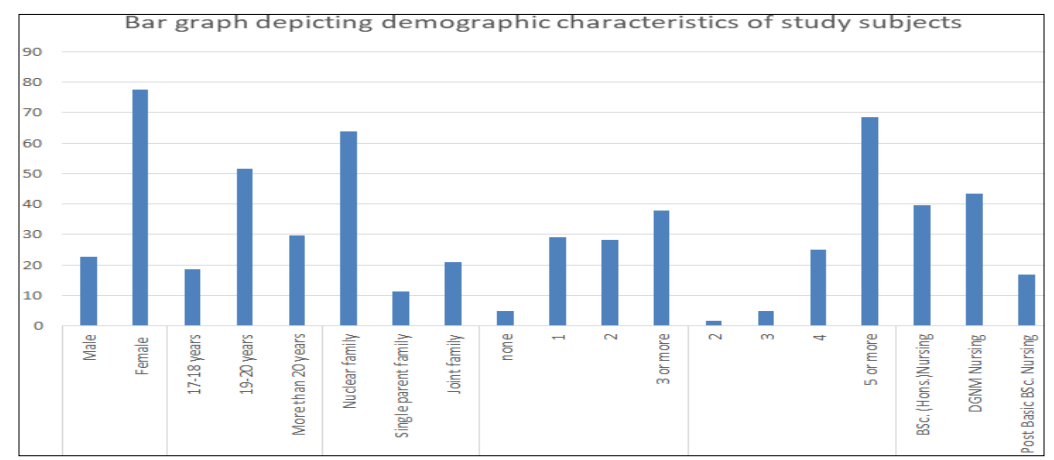

Figure I.Frequency Distribution of Study Subjects by their Demographic Characteristics 


\section{Section 2: Findings related to Social Media Usage}

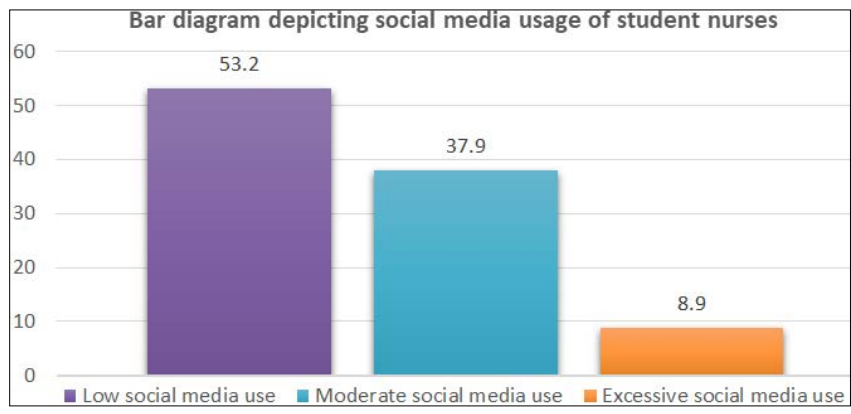

Figure 2.Social Media Usage of Participants

\section{Section 3: Findings related to Family Relationship}

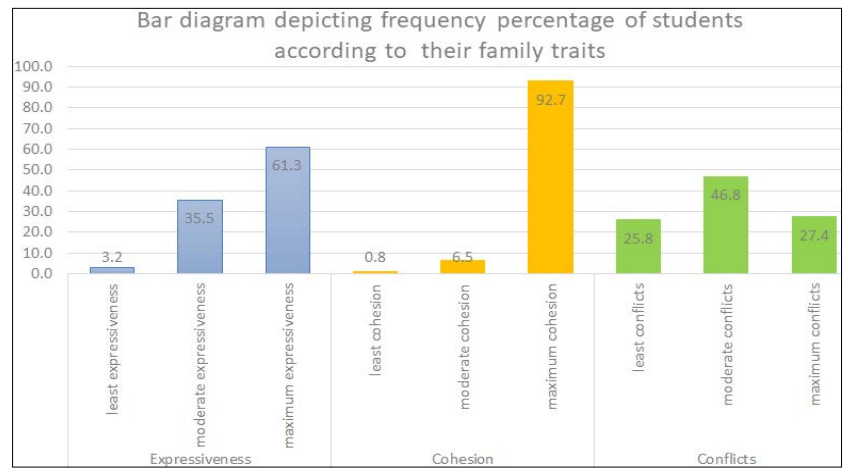

Figure 3.Distribution of Students according to their Family Traits

Section 4: Correlation between Family Relationship and Social Media Use

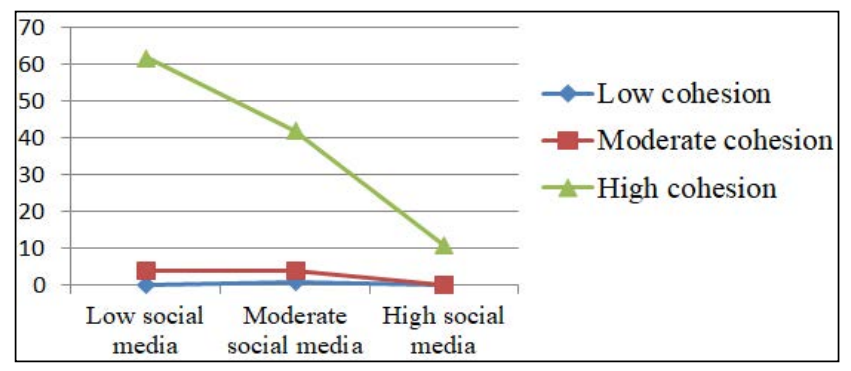

Figure 4.Social Media and Cohesion within the Family

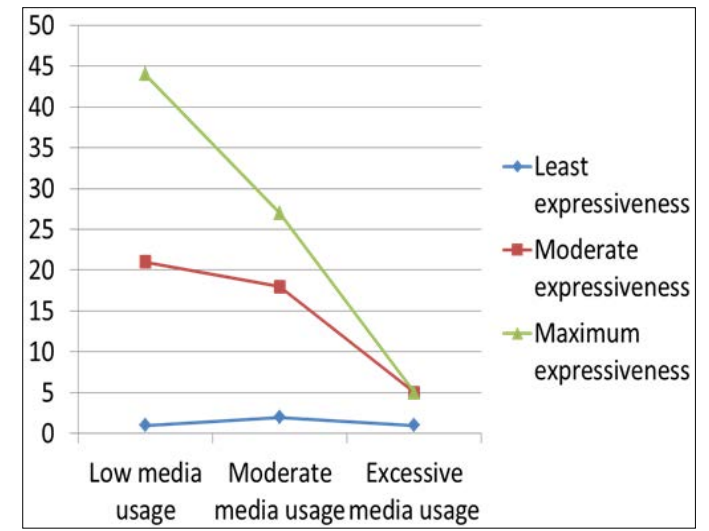

Figure 5.Social Media and Expressiveness in the Family

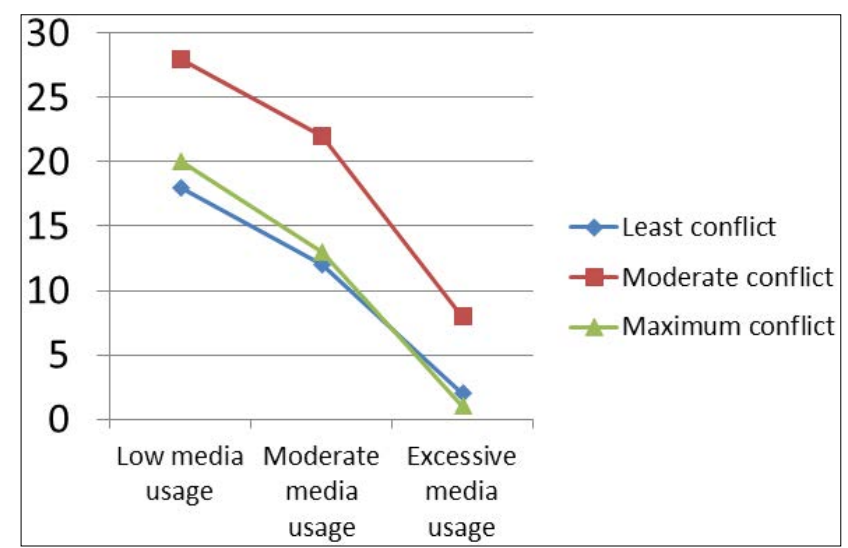

Figure 6.Social Media and Conflicts in the Family The majority of the study subjects, as shown in Figure 1, were females (77 \%) and were from DGNM course (44\%) and $88.7 \%$ of them had access to social media sites on personal devices. According to usage, $9 \%$ were found with excessive social media usage, $38 \%$ with moderate, and $53 \%$ with low usage (Figure 2). The family relationship traits, as indicated in Figure 3, shows maximum expressiveness among families of 76 (61.29\%) students, maximum cohesion among families of 115 (92.74\%) students, and moderate conflicts among families of $58(46.77 \%)$ students. In the linear correlation, there is a direct relationship of cohesion and expressiveness in the family with social media usage and inverse relationship of conflict within the family with social media usage (Figures 4, 5, and 6).

\section{Discussion}

The results of the study reveal that majority of the students were having low to medium social media usage. Regarding family relationships, majority of the students were very expressive and had maximum cohesion with their family members. But when talking about conflicts in families, majority of the students had moderate to maximum conflicts, $46.8 \%$ and $27.4 \%$ respectively. The study shows that there is a direct correlation between expressiveness and cohesion within the family and social media usage by the student nurses and an inverse relationship between conflicts within the family and social media usage. The present study reveals less impact of social media usage on family relationships except for conflicts within the families which were inversely related to social media usage.

The findings of the present study are supported by the result of another study conducted by Joneé B Watt (May 2016), ${ }^{3}$ to examine the relationship between social media use and family relationships, in California State University, Northridge. The findings of this study suggest that social media does have an influence on family and family communication. Young adults are more positive about social media's impact, whereas, older adults are more concerned that social media is negatively impacting the family and its communication. 
A similar survey was carried by Jose Manju, Lishamol Tomy and Chesneau Christophe, ${ }^{4}$ with an aim to study the impact of social media on a student's family relationships and academic performances. The study findings revealed that $99 \%$ of the college students are consumers of social media, mostly accessing these sites through mobile phones and they subscribed to social networking sites mostly for entertainment or to meet their friends followed by academic benefits. The study also revealed that students found more happiness while spending time with parents than with friends and social media and the majority of students (61\%) said that the use of social media does not affect their family relationships.

\section{Conclusion}

Social media usage has become very common among students and has affected their daily lives. The study is conducted to examine the impacts of students' usage of social media sites on their family relationships. The study reveals that the students are using social media sites variably, and it has a significant impact on their family relationships. The utilisation of social media among students should be for constructive reasons and should be an aid to the family relationships and other such relationships, not their alternatives and can be used for instructive purposes, for example, securing or sharing data, looking for help from companions, colleagues or educators to get their questions explained, and not just for enjoyment purposes or to waste their time.

\section{Source of Funding: None}

\section{Conflict of Interest: None}

\section{References}

1. Salgür S [Internet]. How does the use of social networking affect family communication of teenagers?; [cited 2020 May 12]. Available from: https://www. academia.edu/26014442/how_does_the_use_of_ social_networking_affect_family_communication_ of_teenagers

2. We are Social [Internet]. Digital 2019: Global Internet Use Accelerates - We Are Social; 2021 Jan 31 [cited 2020 May 15]. Available from: https://wearesocial. com/blog/2019/01/digital-2019-global-internet-useaccelerates

3. Watt Jonee B [Internet]. Effects of social media use on family relationships; [cited 2020 May 17]. Available from: http://dspace.calstate.edu/bitstream/ handle/10211.3/173317/watt-Jonee-thesis-2016. pdf?sequence $=1$

4. Jose M, Tomy L, Chesneau C. Impact of social media in academic performance and family relationships among college students. Onl J Dist Edu [Internet]. 2021 [cited 2020 May 20];9(1). Available from: https://tojdel.net/ journals/tojdel/articles/v09i01/v09i01-11.pdf [Google Scholar] 